\title{
Effect of Saliva in oral health of post menopausal women
}

\author{
Deepthy.B.Nair
}

\begin{abstract}
The menopause is physiological changes in women that give rise to adaptive changes at both systemic and oral level. As we all begin to reach an older age, dental health and hygiene becomes a major concern. The dentist is often the first person to appreciate numerous changes that are experienced throughout the body during menopause. Oral discomfort is found in many menopausal women in addition to general climacteric complaints. The principal pre-and post-menopausal oral symptoms are dry mouth, sensation of painful mouth (PM) due to various causes and less frequently burning mouth syndrome

Objective: The study was conducted to evaluate the effect of menopause on saliva and dental health. The $\mathrm{pH}$ and oral and hygiene status were determined in regularly menstruating and postmenopausal women who are not on hormone replacement treatment.

Materials and methods: The study was performed on 25 healthy post-menopausal women patients and 25 healthy non menopausal women selected from patients who attended the out patients section of Saveetha Dental College and Hospitals. The patients were asked to relax and pool their saliva and then was collected in graduated test tube. The pH was measured using litmus paper. Oral Hygiene Index and Russel's periodontal index was clinically measured
\end{abstract}

\section{Introduction}

Menopause is a permanent cessation of menstruation and is physiologic process which typically occurs in the 5th decade. Many physiological changes take place due to decreased ovarian estrogen production during this period. Estrogen deficiency may cause several problems such as hot flushes, sweating, osteoporosis, cardiovascular disease, cognitive disease, uro-genital infections and skin changes. Among these osteoporosis is given more priority. Decreasing mineralization of the osseous system, pathological changes aggravate in the periodontium. Bone remodeling is coupled process of bone resorption followed by bone formation. At cellular level, osteoclast promote bone resorption by stimulating production of acid and enzymes that dissolve proteins. Osteoclasts are assisted by transcription factor PU1. Osteoblast promote bone formation by protein matrix primarily consisting of collagen that is son calcified resulting in mineralizing of bone. Bone loss occur when there is imbalance between bone formation and resorption. The activation of osteoclasts is regulated by various molecular signals, of which RANKL (receptor activator of nuclear factor kappa-B ligand) is one of best studied. This molecule is produced by osteoblasts and other cells (e.g. lymphocytes), and stimulates RANK (receptor activator of nuclear factor $\mathrm{KB}$ ). Osteoprotegerin (OPG) binds RANKL before it has an opportunity to bind to RANK, and hence suppresses its ability to increase bone resorption. RANKL, RANK and OPG are closely related to tumor necrosis factor and its receptors. The role of the Wnt signaling pathway is recognized, but less well understood. Local production of eicosanoids and interleukins is thought to participate in the regulation of bone turnover, and excess or reduced production of these mediators may underlie the development of osteoporosis.

Menopause is associated with few years of rapid bone loss attributed to lower circulating level of $17 \beta-$ estradiol related to primarily to loss of estrogen mediated inhibition of bone resorption without compensatory formation.

Saliva plays an important role in protecting oral tissues and preventing foreign material from entering the body. Many studies reveal that salivary $\mathrm{pH}$, buffering capacity (BC) and flow rate play important roles in the oral mucosal defence. When the salivary flow rate is reduced, susceptibility to various oral diseases is enhanced.

\section{Results}

The study consisted of 25 healthy menopausal and non menopausal women to evaluate the correlation between $\mathrm{Ph}$ and periodontal disease. Our result showed increased OHI and russel's indices produce a significant increase in periodontal disease. It also reveals that reveals that there is a distinct decrease in the salivary $\mathrm{pH}$ and flow rate in postmenopausal women which gives route to poor oral hygiene and more susceptibility to oral physiological changes. Therefore, with aging in females, substance of preventive dentistry increases 

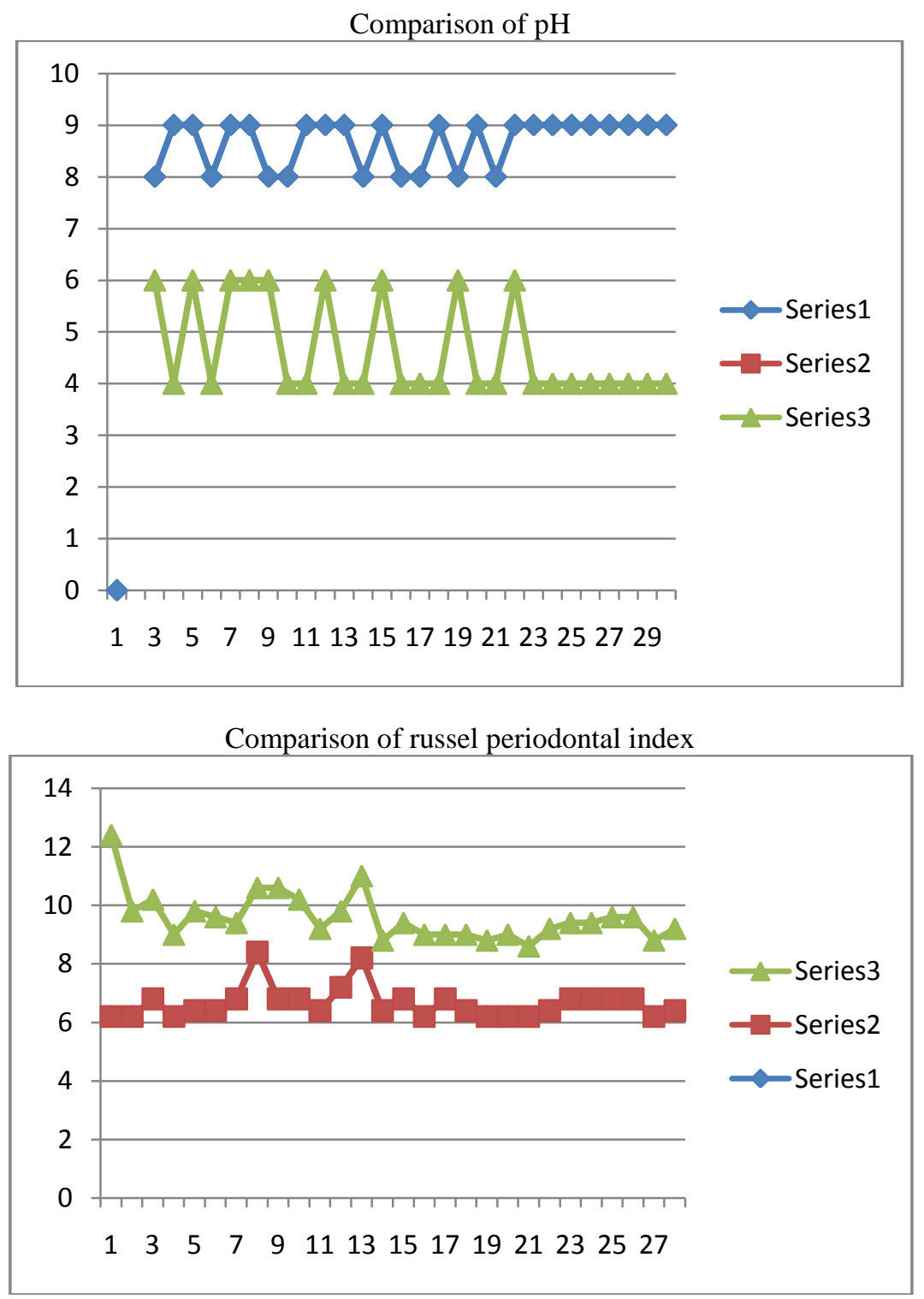

Comparison of OHI

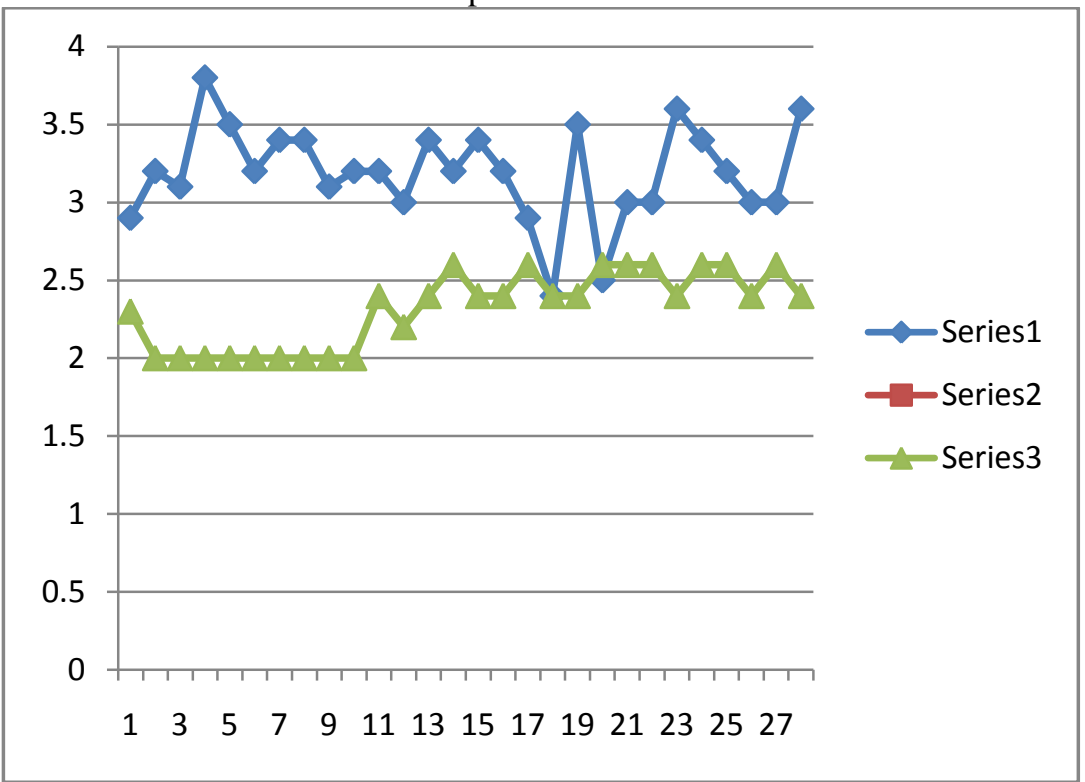


Effect Of Saliva In Oral Health Of Post Menopausal Women

\begin{tabular}{|l|l|l|l|}
\hline & $\begin{array}{l}\text { Post menopausal women } \\
\text { mean[sd] }\end{array}$ & $\begin{array}{l}\text { Premenopausal women } \\
\text { mean[sd] }\end{array}$ & P value \\
\hline $\mathrm{pH}$ & $4.579 \pm 1.01$ & $8.57 \pm 0.507$ & 0.43 \\
\hline Russel & $6.67 \pm 0.61$ & $3.01 \pm 0.859$ & 0.24 \\
\hline OHI & $3.16 \pm 0.32$ & $2.252 \pm 0.24$ & 0.32 \\
\hline
\end{tabular}

\section{Discussion}

The female hormone estrogen influences many physiological and psychological functions. Some studies have reported no change in salivary flow rate after menapause while other studies have shown lower flow rates in postmenopausal women. OHI values of the postmenopausal women were statistically significantly higher than those of the control group which means that oral hygiene of the postmenopausal women was worse than that of the menstruating women. Endocrinal alteration induced bone resorption appears to be the principle pathogenic mechanism underlying accelerated bone loss in postmenopausal women with no direct relationship between the two phenomena. Female gender-related hormonal situations, such as pregnancy- and pubertyassociated gingivitis are known as temporary periodontal diseases. In literature, there are very few studies that correlate only menopause or an estrogen-deficient state to susceptibility to periodontal disease. Though, systemic bone loss may be a risk indicator for periodontal destruction, and augmented rates of bone mineral density loss after menopause are coupled with greater risk of tooth loss. Therefore, avoidance and management of osteoporosis after menopause could also have enhanced future oral health consequences

\section{Conclusion}

In post-menopausal women, alterations of the oral cavity are related to the hormone alterations that characterize these patients and to physiological aging of the oral tissues, potentially giving rise to periodontitis.

\section{References}

[1]. Frutos R, Rodriguez S, Miralles-Jorda L, Machuca G. Oral manifestations and dental treatment in menopause. Med Oral. 2002 JanFeb; 7(1):26-30, 31-5. 2.

[2]. Laine M, Leimola-Virtanen R. Effect of hormone replacement therapy on salivary flow rate, buffer effect and pH on perimenopausal and postmenopausal women. Arch Oral Biol. 1996; 41(1):91-6.

[3]. Sewon L, Laine M, Karjalainen S, Leimola-Virtanen R, Hiidenkari T, Helenius H. The effect of hormone replacement therapy on salivary calcium concentrations in menopausal women. Arch Oral Biol. 2000 Mar; 45(3):201 - 6

[4]. Rose FL, Kaye D. Internal medicine for dentistry.in: chapter 14 endocrinology. Ed. Bartuska DG. 2nd Ed. St lois. Mosby Company 1990; p 1075.

[5]. Matthews KA. Myths and realities of the menopause. Psychosom Med. 1992;54:1-9.

[6]. Brace M, McCauley E. Oestrogens and psychological well-being. Ann Med. 1997;29:283-90

[7]. Lopez BC, Perez MG, Soriano YJ. Dental considerations in pregnancy and menopause. J Clin Exp Dent.2011;3:e135-44.

[8]. Thompson IO, van der Bijl P, van Wyk CW, van Eyk AD. A comparative light-microscopic, electron-microscopic and chemical study of human vaginal and buccal epithelium. Arch Oral Biol. 2001;46:1091-8.

[9]. Leimola-Virtanen R, Pennanen R, Syrjänen K, Syrjänen S. Estrogen response in buccal mucosa - A cytological and immunohistological assay. Maturitas. 1997;27:41-5.

[10]. Välimaa H, Savolainen S, Soukka T, Silvoniemi P, Mäkelä S, Kujari H, et al. Estrogen receptor-beta is the predominant estrogen receptor subtype in human oral epithelium and salivary glands. J Endocrinol.2004;180:55-62.

[11]. Cao M, Shu L, Li J, Su J, Zhang W, Wang Q, et al. The expression of estrogen receptors and the effects of estrogen on human periodontal ligament cells. Methods Find Exp Clin Pharmacol. 2007;29:329-35

[12]. Friedlander AH. The physiology, medical management and oral implications of menopause. J Am Dent Assoc. $2002 ; 133: 73-81$.

[13]. Merskey H, Bogduk N. Classification of Chronic Pain. Seattle, WA: IASP Press; 1994. pp. 59-71. 